ESPAÇO TEMÁTICO: ESTADO, AUTORITARISMO E LUTA DE CLASSES

\title{
A democracia brasileira e seus inimigos
}

Everton Rodrigo Santos ${ }^{1}$

https://orcid.org/0000-0002-6270-3196

Henrique Carlos de O. de Castro ${ }^{2}$

https://orcid.org/0000-0001-8976-838X

\author{
Fábio Hoffmann ${ }^{3}$ \\ https://orcid.org/0000-0003-4374-521
}

${ }^{1}$ Universidade Feevale, Programa de Pós-Graduação em Diversidade Cultural e Inclusão Social, Novo Hamburgo, RS, Brasil

${ }^{2}$ Universidade Federal do Rio Grande do Sul, Programa de Pós-Graduação em Ciência Política, Porto Alegre, RS, Brasil ${ }^{3}$ Universidade Federal de Pelotas, Programa de Pós-Graduação em Ciência Política, Pelotas, RS, Brasil

\section{A democracia brasileira e seus inimigos}

Resumo: O objetivo central deste artigo é demonstrar que a democracia inercial no Brasil tem buscado resolver seus impasses valendo-se do uso do hardball na política, uma espécie de aplicação radical da lei, à revelia das instituições democráticas, num contexto de judicialização da política e ascensão do populismo. O autoritarismo tem-se revestido de outras formas de atuação neste início de século. O trabalho aponta de forma preliminar para dois exemplos de hardball recentes: o uso de pedidos de impeachments na política brasileira para defenestrar os adversários políticos (pelo Legislativo), com êxito em contextos de crise econômica, e o protagonismo da Lava Jato (pelo Judiciário), no combate à corrupção num contexto crescente de insatisfação com a democracia e suas instituições. Para tanto, utilizamos, como base empírica deste trabalho, os bancos de dados do Instituto Brasileiro de Geografia e Estatística, Datafolha e Pesquisa Mundial de Valores (WVS).

Palavras-chave: Democracia Inercial. Hardball. Autoritarismo. Populismo.

\section{Brazilian democracy and its enemies}

Abstract: The main objective of this article is to demonstrate that inertial democracy in Brazil has sought to resolve its impasses by using hardball in politics, a kind of radical application of the law, in spite of democratic institutions, in a context of judicialization of politics and the rise populism. Authoritarianism has taken on other forms of action at the beginning of this century. The work points in a preliminary way to two recent examples of hardball: the use of requests for impeachments in Brazilian politics to defend political opponents (by the Legislative), successfully in contexts of economic crisis, and the role of "Lava Jato" (by the Judiciary), in the fight against corruption in a growing context of dissatisfaction with democracy and its institutions. For this purpose, we use, as an empirical basis of this work, the databases of the Brazilian Institute of Geography and Statistics, Datafolha and World Values Survey (WVS).

Keywords: Inertial Democracy. Hardball. Authoritarianism.Populism

Recebido em 01.05.2020. Aprovado em 22.05.2020. Revisado em 08.09.2020.

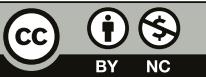

Este é um artigo publicado em acesso aberto (Open Access) sob a licença Creative Commons Attribution NonCommercial, que permite uso, distribuição e reprodução em qualquer meio, sem restrições desde que sem fins comerciais e que o trabalho original seja corretamente citado. 


\section{Introdução}

O Brasil tem apresentado um declínio constante de seu apoio à democracia e suas instituições. Várias são as evidências, como se pode ver, por exemplo, na última Pesquisa Mundial de Valores (WVS), na $7^{\mathrm{a}}$ onda (2015/2019): perguntados sobre "qual a importância de se ter um líder forte no país que não tenha medo de passar por cima do parlamento e das eleições", 23,9\% acham "ótimo" ter este líder e 41,6\% acham "bom". Não foi por acaso que, em outubro de 2018, Jair Bolsonaro do PSL, um ex-capitão do exército brasileiro e deputado federal da extrema direita, obteve $49,8 \%$ dos votos no segundo turno das eleições presidenciais no País, contra 40,5\% da candidatura de Fernando Haddad do PT, da esquerda moderada. (INGLEHART et al., 2014; CASTRO; RANINCHESKI; CAPISTRANO, 2018).

Paralelamente ao declínio do apoio difuso à democracia e à ascensão de um candidato populista de direita, têm aumentado os movimentos antissistema já há algum tempo no País, com os perdedores da competição eleitoral não aceitando a derrota nas urnas. Há também um crescimento considerável nos números de decisões judiciais sobre corrupção envolvendo não somente a classe política, mas também a classe empresarial que circunda o Estado brasileiro. Com a perda significativa de legitimidade das instituições democráticas, em especial, dos poderes Executivo e Legislativo, observamos um protagonismo crescente nas últimas décadas, não propriamente capitaneado pelos militares como em décadas pretéritas, mas sobretudo pelo Judiciário. Observamos, a partir da Constituição de 1988, contendas políticas serem dirimidas na Justiça, o que a bibliografia especializada tem chamado de judicialização da política (VIANNA et al., 2014).

Este é um fenômeno que pode ser explicado, em parte, pela percepção generalizada de insatisfação com o funcionamento e a queda da confiança institucional nas democracias no mundo e, particularmente, no Brasil (CATTERBERG; MORENO, 2005; MOISÉS; MENEGUELLO, 2013; CASTELLS, 2015).

Na América Latina, como argumenta Baquero (2018), temos tido uma democracia que o autor conceitua como inercial, em outras palavras, uma democracia que, em termos institucionais, avançou de certa forma nos últimos anos, mas, em termos substanciais, tais como, crescimento econômico, investimentos sociais e cultura política aderente às instituições, se mantém estagnada e inerte na região. Neste descompasso entre os aspectos institucionais e substanciais da democracia, há espaço para o surgimento de um fenômeno que tem substituído os golpes clássicos na América Latina, que Levitsky e Ziblatt (2018) chamam de hardball, ou seja, o jogo duro constitucional: o uso radical da lei para subverter a própria democracia. Isso posto, num contexto em que as instituições jurídicas foram aquelas que menos perderam legitimidade, como veremos. Este fato tem indicado que os inimigos da democracia não são mais externos ao regime, mas internos a ele. Este fenômeno ocorre também em um contexto crescente de ascensão do populismo no mundo (INGLEHART; NORRIS, 2016) e, particularmente, no Brasil. Autores como Inglehart e Norris (2016) explicam este novo populismo como uma espécie de Cultural Backlash, um retrocesso nos valores culturais que coloca gerações mais velhas e com pouca educação formal apoiando candidaturas e partidos políticos populistas. No Brasil, teríamos este fenômeno com contornos particulares, um ressentimento das classes e regiões mais abastadas do país com forte apelo aos valores tradicionais. Guardadas as idiossincrasias, em ambos os casos, há um esmagamento da classe média; no entanto, o fenômeno entre nós não pode ser considerado um retrocesso, "uma vez que nunca chegamos lá" (CASTRO, 2019).

Estabelecido sumariamente nosso quadro teórico de análise, buscamos investigar em que medida a democracia inercial no Brasil (BAQUERO, 2018) tem buscado resolver seus impasses políticos se valendo do uso do hardball (LEVITSKY; ZIBLATT, 2018), por parte das elites incumbentes, à revelia das instituições democráticas, num contexto de judicialização da política (VIANNA et al., 2014) e ascensão do populismo (INGLEHART; NORRIS, 2016).

Objetivando responder a esta problemática, o artigo foi dividido em dois momentos, no primeiro, "Democracia inercial e o uso do hardball na política brasileira", apresenta-se o quadro teórico conceitual, caracterizando a democracia inercial, bem como o fenômeno do hardball como opção das elites neste quadro de estagnação democrática para resolução de impasses políticos e atalho da competição eleitoral. Num segundo momento, "Os dois grandes tropeços da democracia brasileira", elenca-se os casos de hardball mais significativos na política brasileira das últimas décadas (impeachment de Collor em 1992 e Dilma em 2016) e o protagonismo da Lava Jato a partir de 2014, que caracterizam a nova forma de ataque à democracia, 
contrapondo-se aos clássicos golpes de Estado na América Latina. O autoritarismo tem-se revestido de outras formas de atuação.

Recorrendo à pesquisa quantitativa, utilizamos, como base empírica deste artigo, o banco de dados do Instituto Brasileiro de Geografia e Estatística (IBGE), para os cálculos do Produto Interno Bruto (PIB), PIB per capita e PIB corrente (1990/2018), bem como o banco de dados do DataFolha (1990/2018) e da Pesquisa Mundial de Valores (WVS), principalmente os dados da $7^{\mathrm{a}}$ onda inéditos no Brasil. Posteriormente, foram utilizados o software SPSS para análise dos bancos e testes estatísticos de regressão múltipla.

\section{Democracia inercial e o uso do hardball na política brasileira}

Se a democracia tem passado por momentos críticos onde ela já está há muito tempo estabelecida, na América Latina, e mais especificamente no Brasil, os problemas que ela vem acumulando são mais agudos e de ordem socio-histórica. Primeiro, porque a formação do Estado e a gênese da sociedade se deram de forma diversa da que ocorreu com os países do hemisfério norte. Segundo e, consequentemente, porque, no Brasil, traços como autoritarismo, patrimonialismo e clientelismo permanecem ainda fortes e determinantes no modo de funcionamento do complexo institucional implantado ao longo do processo de redemocratização. Os brasileiros têm se mostrado mais dispostos a respostas autoritárias, como uma intervenção militar para resolução de crises agudas, vivendo uma espécie de nostalgia da ditadura (CASTRO, 1996, 2014; BITTENCOURT, 2020).

$\mathrm{Na}$ esteira dos estudos de cultura política e fazendo avançar a análise sobre as sociedades da América Latina (e do Brasil, em particular), Baquero (2018) propõe que a democracia latino-americana seja conceituada como uma democracia inercial. Em outras palavras, uma democracia estagnada, que "segue um padrão no qual mudanças econômicas, políticas e sociais ocorrem dentro de uma continuidade de um modelo político que não se altera significativamente, independente da ideologia do governo incumbente" (BAQUERO, 2018, p. 25). "Tal situação, no contexto atual, pode não redundar numa regressão autoritária ou colapso institucional [...], mas o dano maior se dá na instabilidade política permanente" (BAQUERO, 2018, p. 30). Assim, neste tipo de democracia, temos um terreno propício para o aparecimento de um fenômeno recente aberto na política brasileira, principalmente a partir de 1988, com a judicialização da política e o uso do hardball na política.

\section{A judicialização da política e o ativismo judicial}

A judicialização da política, como argumenta Vianna et al. (2014), é um fenômeno que se caracteriza pelo fato de levar para a esfera judicial uma contenda que poderia (ou talvez devesse) ter sido resolvida na esfera política, uma espécie de provocação ao judiciário. Dessa forma, o ativismo judicial como uma contra face desta mesma moeda, seria uma atuação proativa do Judiciário, provocado pela política. São fenômenos conexos: à medida que a política se desvaloriza, o Judiciário adquire mais credibilidade e demanda. Barboza e Kozicki (2012) argumentam que a bibliografia especializada tem apontado alguns facilitadores desse processo de judicialização da política no Brasil a partir dos anos 1980, tais como: a) a própria Constituição de 1988; b) a universalização do acesso à justiça; c) a ampliação da comunidade de intérpretes da Constituição, entre outras, pode-se acrescentar; d) a crise de representação política do modelo liberal; e) os escândalos de corrupção publicizados pelas diferentes mídias; e f) as novas tecnologias de informação que dão enorme visibilidade à arena política.

De fato, a judicialização da política beneficiou setores da esquerda nas últimas décadas, buscando compensar um parlamento muitas vezes conservador na promulgação de leis a um judiciário mais liberal e, portanto, mais sensível às questões das minorias. Por outro lado, os setores de uma direita conservadora também se valeram, nos últimos anos, da judicialização da política, como veremos adiante, tanto no episódio do impeachment da ex-presidente Dilma Rousseff em 2016, como nas eleições de 2018. O problema posto de fundo, tanto à esquerda quanto à direita, é que o Poder Judiciário não teria legitimidade democrática para deliberar, posto que não é um poder eleito, não representa o desejo majoritário da sociedade para tomar decisões políticas que não lhe caberia, como princípio. 


\section{O uso do hardball na política brasileira}

Levitsky e Ziblatt (2018) usam o termo hardball para se referir a uma nova modalidade de jogo das elites políticas nestas democracias, ou seja, jogam duro, jogam sujo, no sentido de, mesmo dentro do que é permitido no limite das leis, pelas regras, fazem uma leitura mais rígida das leis para favorecerem os interesses autoritários e atropelarem a competição política. Como exemplos mais recentes de hardball, podemos citar o impeachment de Fernando Lugo, no Paraguai, em 2012, de Dilma Rousseff, no Brasil, em 2016, e de Pedro Pablo Kuczynski, no Peru, em 2018. Todos os processos feitos, em tese, dentro da lei.

Em outras palavras, os autores aludem para o fato de que as democracias possuem regras escritas e não escritas, sendo que tanto as regras escritas quanto as não escritas são imprescindíveis para o bom funcionamento da democracia. As regras não escritas implicam tolerância mútua e reserva institucional. Para corroborar nosso argumento, Levitsky e Ziblatt (2018) lembram do direito divino dos reis, em que nenhuma regra moral limitava legalmente seus poderes, pois eles eram ungidos por crenças religiosas. Assim, alguns excessos reais sobre os seus súditos eram absolutamente legais; no entanto, por muitas vezes atentarem contra os costumes da época, constrangiam o uso do poder real. A transgressão dessas regras por parte dos reis levava frequentemente a revoltas e guerra civil, o que os monarcas evitavam. Dito de outra forma, os aspectos culturais da sociedade são essenciais para a manutenção ou ruptura de um sistema político.

Ocorre que, com a queda da satisfação nas instituições da democracia liberal, entre elas, de maneira frontal, o executivo e o legislativo, temos uma judicialização recorrente das questões políticas, em contextos de crise econômica, possibilitando o uso deste hardball, como veremos nos casos empíricos evidenciados a seguir. Em outras palavras, o diabo está nos detalhes.

\section{Os dois grandes tropeços da democracia brasileira: os impeachments de Collor à Dilma}

Desde Marx (1986), passando por Lipset (1967), a dimensão econômica ainda possui efeitos importantes sobre as relações humanas, as instituições políticas e a própria democracia. Patamares muito baixos de crescimento econômico, distribuição de renda e desigualdade no mundo têm ameaçado a crença na democracia e nos direitos e liberdades fundamentais (PIKETTY, 2013; CASTELLS, 2018). No Brasil, não foi diferente, tanto no impeachment de Collor, em 1992, como no impeachment de Dilma, em 2016, ou mesmo na prisão do ex-presidente Lula, em 2018, que são exemplos de tropeços da jovem democracia brasileira combinados com parco crescimento do PIB. Quando observamos, no Gráfico 1, a variação do PIB brasileiro nos últimos 35 anos e seus respectivos períodos recessivos, percebemos o quão importante a economia é para a política e para a sustentação da democracia.

Cada período recessivo da economia correspondeu a uma inflexão poderosa sobre a arena política. A queda do PIB no início dos anos 80 em - 8,5\% levou à abertura política e ao declínio do regime autoritário

\section{Gráfico 1 - Variação do PIB}

\begin{tabular}{|l|cccc}
\hline \multicolumn{5}{c}{ As grandes crises } \\
\hline Anos & \multicolumn{2}{c}{$1981-1983$} & $1989-1992$ & $2014-2016$ \\
\hline Duração (trimestre) & \multicolumn{2}{c|}{9} & 11 & 11 \\
\hline Variação do PIB & -7.2 & & \\
& -7.4 & & \\
& -7.6 & & -7.7 & \\
& -7.8 & & & \\
& -8 & & & -8.6 \\
\hline
\end{tabular}

Fonte: Comitê de Datação de Ciclos Econômicos, FGV (2018). Acesso ao site em 15 de novembro de 2019 https:// portalibre.fgv.br/codace. 
(1981/1983), que já se encontrava muito longe dos efeitos do milagre econômico nos anos 70. No final dos anos 80 e início dos 90 (1989/1992), a queda do PIB em -7,7\% deu ensejo ao impeachment do primeiro presidente eleito democraticamente, Fernando Collor de Mello, em 1992. Entre (2014/2016), a queda do PIB em -8,6\% levou ao impeachment da Presidente Dilma Rousseff, em 2016, que havia sido eleita democraticamente em 2014 para o seu segundo mandato.

Nessas últimas décadas, dois presidentes eleitos democraticamente não resistiram às recessões, tanto Collor quanto Dilma caíram ${ }^{1}$. Outro dado importante, ao lado da economia, é a dimensão da cultura política como um fator importante de sustentação da democracia. A medida em que a popularidade do presidente cai, aumentam os pedidos de impeachments (Gráfico 2). Quando olhamos para a direita do Gráfico 2, no governo Collor, que chega a uma avaliação de 68 de ruim ou péssimo, ele teve 29 pedidos de impeachments com um PIB de $-0,5 \%$ em 1992. Dilma 2 chega a $71 \%$ de ruim e péssimo e atinge 34 pedidos de impeachments no Congresso Nacional, alcançando uma queda de -3,6\% do PIB em 2016.

\section{Gráfico 2 - Impeachment X Popularidade}

IMPEACHMENT X POPULARIDADE

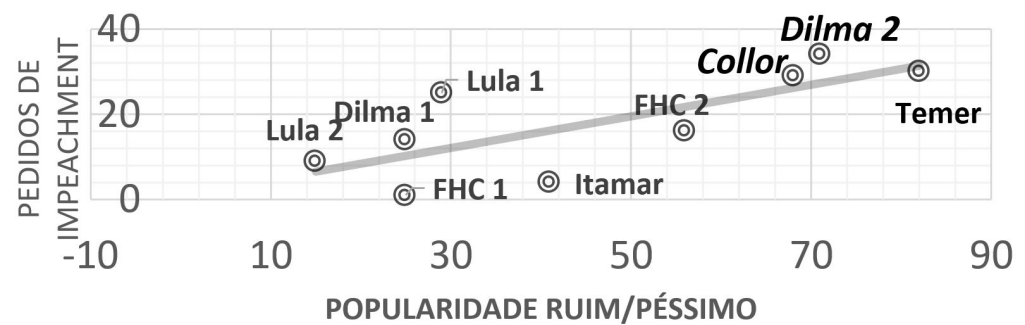

Fonte: Elaborado pelos autores a partir de dados coletados do Portal da Câmara Federal (1992/2018). Acesso ao site em 09 de novembro 2019, https://www.camara.leg.br/ e dados de pesquisa do Datafolha (2002/2018). Acesso ao site em 05 junho de 2019 http://datafolha.folha.uol.com.br/.

Aplicando-se o teste de regressão múltipla, conforme a Tabela 1, identificamos que as variáveis associadas significativamente com os Pedidos de Impeachments (PI) são o PIB Corrente (PIBC), o PIB Per Capita (PIBPC) e a Popularidade Negativa dos Presidenciáveis (PNP). A variável que mais contribuiu para os pedidos de Impeachment foi a popularidade. Quanto maior o percentual de rejeição ao presidente, maior o número de pedidos de impeachment. Outra variável que está também associada inversamente ao número de pedidos de Impeachment é o PIBPC, indicando que, quanto menor PIBPC, maior é o número de pedidos de Impeachment no Congresso. Estas três variáveis, (PNP), (PIBPC) e (PIBC) são determinantes para os pedidos de impeachments, para o uso dos hardballs.

O Presidente Temer teve um patamar de ruim e péssimo de $82 \%$ e um número de 30 pedidos de impeachments, (Gráfico 2) em seu curto tempo de gestão; não caiu, mas seu governo permaneceu instável ${ }^{2}$. Assim, podemos afirmar que Presidentes da República com patamares acima de 60\% de ruim ou péssimo, combinados com crescimento negativo da economia ou com parco crescimento, tendem a cair ou manter-se em governos instáveis. Nessa situação, foram impedidos Collor e Dilma; Michel Temer, por sua vez, permaneceu instável.

O que vemos aqui, no uso indiscriminado de pedidos de impeachments nos últimos anos da República (162 pedidos), caracteriza aquilo que Levitsky e Ziblatt (2018) chamaram de hardball, ou seja, o jogo duro constitucional, que consiste na estrita aplicação da lei dentro de democracias, mas que, ao mesmo tempo, destrói o espírito da lei e da própria democracia, pois o hardball atropela a competição política e viola as regras não escritas da democracia.

O impeachment, como está sendo usado no Brasil, viola as regras democráticas e o espírito da lei. De 1990 a 2018, de Collor a Temer, foram em média quase seis pedidos de impeachment por ano, tendo eleições regulares a cada dois anos no País para diferentes instâncias. Ou seja, as eleições parecem não ser o suficiente para resolver a contenda política. 
Tabela 1 - Resultados do Modelo de Regressão Múltipla

\begin{tabular}{|c|c|c|c|c|c|c|}
\hline \multicolumn{7}{|c|}{ Coefficients $^{\mathrm{a}}$} \\
\hline & \multirow{2}{*}{$\begin{array}{c}\text { Model } \\
\text { B }\end{array}$} & \multicolumn{2}{|c|}{ Unstandardized Coefficients } & \multirow{2}{*}{$\begin{array}{c}\text { Standardized } \\
\text { Coefficients }\end{array}$} & \multirow{2}{*}{$\mathbf{t}$} & \multirow{2}{*}{ Sig. } \\
\hline & & Std. Error & Beta & & & \\
\hline \multirow{5}{*}{1} & (Constant) & $-6,913$ & 5,438 & & $-1,271$ & ,219 \\
\hline & PIB & 1,280 & ,707 &, 344 & 1,810 & ,086 \\
\hline & PIBC & $1,099 \mathrm{E}-5$ &, 000 & 7,905 & 2,703 & ,014 \\
\hline & PIBPC &,- 002 &, 001 & $-7,757$ & $-2,629$ &, 017 \\
\hline & PNP & 35,851 & 9,283 & ,706 & 3,862 & ,001 \\
\hline \multicolumn{7}{|c|}{ a. DependentVariable: PI } \\
\hline
\end{tabular}

Fonte: Elaborados pelos autores a partir de dados econômicos coletados no IBGE (1992/2018). Acesso ao site em 08 de agosto de 2019, https://www.ibge.gov.br/

Obs.: O modelo de regressão múltipla apresentou bom desempenho na predição dos pedidos de Impeachment em relação às variáveis PIB, PIB Per Capita e Popularidade (R2 0,522; p=0,005). Foi utilizado o pacote estatístico SPSS v25.

É nesse sentido que, tanto o impeachment de Collor, em 1992, como o de Dilma Rousseff, em 2016, podem ser caracterizados como hardball, mesmo tendo sido legais. As razões alegadas do impeachment de Collor, em 1992, estavam relacionadas ao uso de caixa 2, fraudes, corrupção, contas no exterior, enfim, as justificativas tradicionais para impeachment de presidentes no Brasil. No caso de Dilma, além do fato de várias lideranças estarem envolvidas em corrupção em seu governo, da má administração, do conjunto da obra, aqui houve uma inovação: no impeachment, foram as pedaladas fiscais da presidente em relação às contas públicas ${ }^{3}$. Aliás, manobra fiscal utilizada em larga escala por todos os presidentes eleitos, governadores de estados e prefeitos no País afora.

Note-se que os dois pedidos de impeachment foram legais e não podem ser classificados como querem os governistas, tanto de 1992 como de 2016, como golpes, mas também não podem ser classificados como quer a oposição, como exemplo de bom funcionamento de nossas instituições democráticas, pois, nos dois casos, trata-se de um hardball claro, utilizados pelas lideranças políticas de diferentes partidos, da esquerda à direita para "vencer" o jogo sem competição, burlando regras informais da democracia brasileira ${ }^{4}$. Em outras palavras, a democracia serve para quem tem força política.

\section{O Protagonismo da Lava Jato Diante da Insatisfação com a Democracia}

Este comportamento desviante das instituições democráticas por parte das elites políticas fica mais claro quando observamos o respaldo que elas recebem da opinião pública brasileira. Há uma queda da satisfação com o sistema político vigente no Brasil de acordo com o Gráfico 3: se na $4^{a}$ onda do WVS (1994/1998) $28,40 \%$ da população brasileira declarou estar satisfeita com o sistema político, este pequeno percentual cai ainda mais para 12,80\% na $7^{\mathrm{a}}$ onda (2015/2019). (INGLEHART et al., 2014; CASTRO; RANINCHESKI; CAPISTRANO, 2018).

De fato, quando adentramos o sistema político, verificamos que a confiança nas instituições tem declinado consistentemente no Brasil ao longo da série histórica, como mostra o Gráfico 4. Na $4^{a}$ onda de 1994/1998, $48,70 \%$ das pessoas confiavam no governo federal. Esse percentual caiu mais da metade para $23,10 \%$ na $7^{\mathrm{a}}$ onda 2015/2019 (INGLEHART et al., 2014) Outra queda preocupante é a confiança no Congresso Nacional, pois, se, em 1994/1998, 33,60\% dos brasileiros confiavam no Congresso, na última onda, apenas 16,10\% declararam confiar (INGLEHART et al., 2014). Os partidos políticos foram aqueles que mais decaíram na confiança dos cidadãos, tendo uma queda de 32,50\% em 1994/1998 para 13,70\% em 2015/2019, como podemos constatar 
Gráfico 3 - Satisfação com o sistema político vigente

\section{Satisfação com o sistema político vigente}

$40,00 \%$

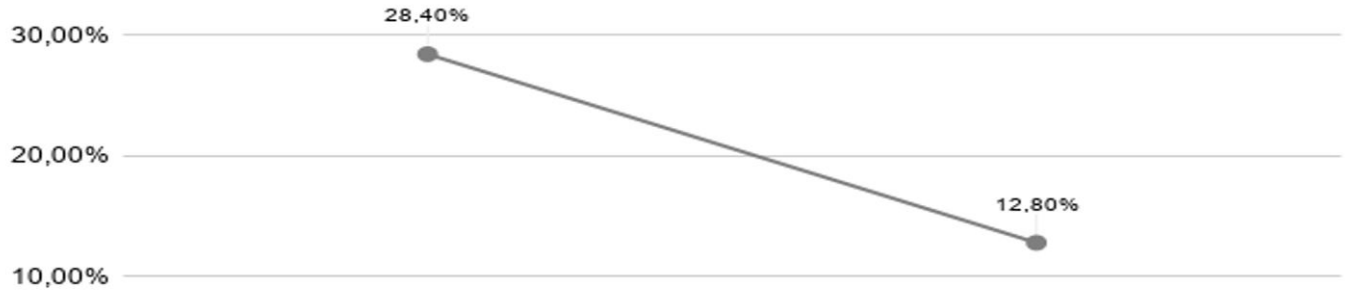

$0,00 \%$

1994-1998

2015-2019

Fonte: Inglehart et al. (2014) e Castro, Ranincheski e Capistrano (2018).

Obs.: Para a construção do gráfico, consideramos apenas a variável satisfação com o sistema político na escala de 6 a 10, em que os dados apresentam apenas os resultados a essas respostas e expressam, na coluna, sua porcentagem e, nas linhas, a série temporal.

\section{Gráfico 4 - Confiança nas instituições}

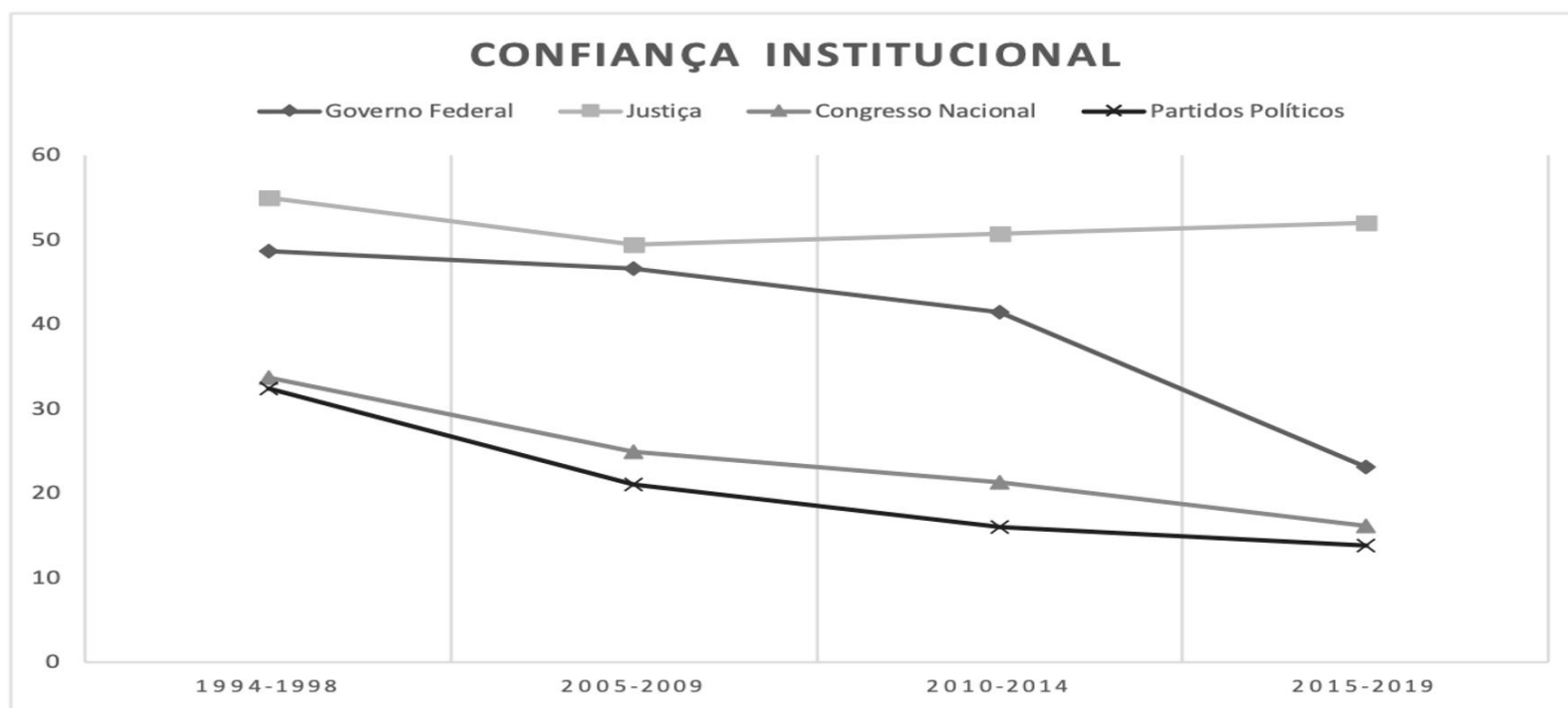

Fonte: Inglehart et al. (2014) e Castro, Ranincheski e Capistrano (2018).

Obs.: Surveys de 1994/1998, 2005/2009, 2010/2014, 2015/2019. Para a construção do gráfico, consideramos apenas a variável "confia totalmente e confia em parte", em que os dados apresentam apenas os resultados a essas respostas e expressam, na coluna, sua porcentagem e, nas linhas, a série temporal.

no Gráfico 4. O fato relevante é que duas instituições centrais do modelo liberal de democracia como partidos políticos e parlamento estão profundamente desacreditadas pela população, que opta pelas saídas personalistas.

Nesse sentido, entendemos que o declínio da satisfação com estas duas instituições centrais do Estado Democrático de Direito dão vazão ao protagonismo do poder judiciário, através do fenômeno tanto da judicialização da política quanto do ativismo judicial no Brasil, principalmente a partir da Constituição de 1988, com o fortalecimento do Ministério Público (MP). A operação Lava Jato constitui-se no caso mais emblemático deste fenômeno recente, principalmente depois do instituto da Delação Premiada, Lei assinada 
por Dilma Rousseff. Esta operação teve início em março de 2014 e constituiu-se num conjunto de investigações que envolveram tanto a Polícia Federal (PF) quanto o Ministério Público (MP), entre outros, o então Juiz Sérgio Moro, investigando crimes de corrupção passiva e ativa, gestão fraudulenta, organização criminosa, formação de quadrilha, desembocando em dezenas condenações e prisões coercitivas, envolvendo tanto gestores públicos de importantes estatais, quanto membros da classe política e empresarial do Brasil e do exterior ${ }^{5}$.

Essa operação desfrutou um enorme prestígio político. O Gráfico 4 corrobora esse argumento na medida em que mostra a justiça como a instituição mais preservada desses desgastes. Ela tinha 55\% de confiança da população em 1994/1998, teve uma pequena oscilação para baixo de 49,5\% em 2005/2009 e voltou a subir para 52,20\% em 2015/2019 (INGLEHART et al., 2014; CASTRO; RANINCHESKI; CAPISTRANO, 2018).

Os escândalos de corrupção da classe política e empresarial que culminaram com a prisão do ex-presidente Lula, em abril de 2018, pela operação Lava Jato, configura-se caso flagrante de judicialização da política que dá espaço para o uso do hardball, aos inimigos a lei. Esse fenômeno colocou o Juiz, Sérgio Moro, com seus poderes constituídos desde a arena judiciária, diretamente na arena política ${ }^{6}$. Este ativismo fica mais explícito, entre outras, na liberação de escutas telefônicas ilegais, bem como em depoimentos de delações premiadas sem base factual, visando impedir a posse do ex-presidente como ministro da casa civil ou mesmo sua eleição em 20187. O STF, através do ministro Gilmar Mendes, já em 2016, determinou a suspensão da nomeação de Lula como ministro da Casa Civil no governo Dilma, respondendo a esta judicialização política tanto do PSDB quanto do PSB (OLIVEIRA, 2016).

O ponto alto desse fenômeno não foi a violação do artigo $5^{\circ}$, inciso LVII da Constituição Federal de 1988, que reza que "Ninguém será considerado culpado até o trânsito em julgado da sentença penal condenatória" (BRASIL, [2016]), e tampouco o Código Civil Penal Brasileiro que reza: dando ao acusado o direito de responder processo em liberdade (BRASIL, 2011), pois ele havia sido condenado somente em segunda instância. O ápice foi o aceite do Juiz Sergio Moro para assumir o Ministério da Justiça do presidente eleito Jair Bolsonaro do PSL, compondo, enquanto membro de uma espécie de partido da justiça, um novo player junto com os militares no governo. As revelações das conversas telefônicas entre o Juiz Sergio Moro e os integrantes do Ministério Público (MP) como o procurador Deltan Dallagnol, pelo site The Intercept Brasil, amplamente divulgados na imprensa, só corroboram nosso argumento não somente do uso da lei, mas também da sua própria violação em nome do combate à corrupção. Não estamos aqui discutindo os méritos da operação, muito menos à corrupção em si, mas a forma como se deu, à revelia do devido processo jurídico legal ${ }^{8}$. Neste processo, de desgaste perante a opinião pública, é compreensível que a democracia vai perdendo gradativamente sua importância e força perante a população brasileira, conforme o Gráfico 5 demonstra. Como podemos observar, $86,90 \%$ dos brasileiros, em 2005/2009, declararam de forma genérica sua importância

\section{Gráfico 5 - Importância da Democracia}

$\begin{array}{lcr}\text { Importância da democracia } & \\ 100,00 \% & & \\ 90,00 \% & 80.10 \% & 79.60 \% \\ 80,00 \% & & \\ 70,00 \% & & \\ 60,00 \% & \\ 50,00 \% & \\ 40,00 \% & \\ 30,00 \% & \\ 20,00 \% & 2010-2014 \\ 10,00 \% & \\ 0,00 \% & 2005-2009\end{array}$

Fonte: Inglehart et al. (2014) e Castro, Ranincheski e Capistrano, (2018).

Obs.: Surveys de 2005/2009, 2010/2014, 2015/2019. Para a construção do gráfico, consideramos apenas a variável “importância da democracia de 6 a 10", em que os dados apresentam apenas os resultados a essas respostas e expressam, na coluna, sua porcentagem e, nas linhas, a série temporal. 
na democracia, todavia, na última onda 2015/2019, há uma queda para 79,6\%. (INGLEHART et al., 2014; CASTRO; RANINCHESKI; CAPISTRANO, 2018).

A operação Lava-Jato é a cristalização da judicialização da política, bem como do ativismo judicial, na sua máxima potência, uma clara investida do poder judiciário, diante do espaço aberto pelos demais poderes constituídos da República. Assim, o uso do hardball, uma forma de ativismo judicial, parece ser o modus operandi no século XXI das elites políticas e econômicas com o apoio de militares e boa parte da opinião pública, bombardeada pelos escândalos de corrupção (CASTELLS, 2015), em detrimento dos golpes clássicos no século XX. A eleição de Bolsonaro contou com o apoio diuturno lavajatista, militar e de importantes setores empresariais, inclusive com vários Generais sendo incorporados ao seu governo. Nesta ordem das coisas, parece que os militares voltam à cena política não mais como uma tragédia, típicas do século passado, mas como uma farsa, para parafrasear Marx (2011) no 18 de Brumário, uma vez que nunca abandonaram seu papel tutelador sobre o sistema político brasileiro (SANTOS, 2010).

\section{Considerações finais}

Este artigo demonstrou que os inimigos da democracia no Brasil têm uma nova modalidade de ataque às instituições democráticas, não mais efetuada por golpes tradicionais ou insurreições, de fora para dentro, mas sobretudo de dentro para fora do regime. Nesse sentido, as elites políticas tanto à esquerda quanto à direita do espectro político e na esteira da judicialização das contendas políticas, buscam resolver seus impasses se valendo do uso do hardball, à revelia das instituições democráticas, num novo contexto agravado pela ascensão do populismo no mundo e em particular no Brasil, nos últimos anos, que levam nossa jovem democracia a um estado inercial.

Consonante com outros trabalhos, fica claro que a democracia não é um caminho natural, mas uma construção social que precisa de congruência com a sociedade. Não se trata unicamente da proposição de mecanismos formais de escolha de dirigentes, mas de algo escrupulosamente trabalhado em termos geracionais. Mesmo assim, como indicam pesquisas nas chamadas democracias avançadas, não há garantia alguma da perenidade de qualquer sistema político: a sua construção ou manutenção depende de permanente decisão.

O trabalho também evidenciou que a cultura política do brasileiro está longe de efetivamente sustentar a democracia em seus aspectos substantivos (conteúdo e instituições), mas tão somente em sua forma (eleições e apoio difuso). Dessa forma, o apelo populista pode ser um canto da sereia para saudosos da ditadura ou para elites descomprometidas com a sociedade. A eleição de Jair Bolsonaro em 2018 e o surgimento de movimentos protofascistas em seu apoio pré e pós-eleitoral são indicativos disso. Nesse sentido, a cultura política pode ser também um inimigo da democracia.

Decerto há inúmeros outros casos que poderiam ser elencados aqui para ilustrar melhor nosso quadro teórico, como a prisão do ex-presidente Michel Temer em março de 2019, pelo juiz Marcelo Bretas, entre outros. Todavia, o espaço deste trabalho nos obriga a fazer recortes ao mesmo tempo que inaugura uma nova agenda de investigação no País. Estes fenômenos abertos no Brasil, com a Constituição de 1988, têm dado vazão à ocorrência do uso do hardball na política brasileira de maneira mais explícita. Seus usos serão tão mais frequentes quanto maior for a incongruência entre economia, política e desigualdade social no País.

\section{Referências}

BAQUERO, M. Democracia Inercial. Porto Alegre: Ed. da UFRGS, 2018.

BARBOZA, E. M. de Q.; KOZICKI, K. Judicialização da Política e Controle Judicial de Políticas Públicas. Revista de Direito GV, São Paulo, n. 8, p. 59-86, jan./jun. 2012.

BERTHOLINI, F; PEREIRA, C. Pagando o preço de governar: custos de gerência de coalizão no presidencialismo brasileiro. Revista de Administração Pública FGV, Rio de Janeiro, n. 4, v. 51, p. 528-550, 2017.

BITTENCOURT, M. A. "Nostalgia da Ditadura” e as eleições de 2018 no Brasil: uma proposta de explicação. 2020. 50f. Dissertação (Mestrado em Cultura Política) - Universidade Federal do Rio Grande do Sul, Porto Alegre, 2020.

BRASIL. [Constituição (1988)]. Constituição da República Federativa do Brasil de 1988. Brasília, DF: Presidência da República, [2016]. Disponível em: http://www.planalto.gov.br/ccivil_03/Constituicao/Constituicao.htm. Acesso em: 26 abr. 2019. 
BRASIL. Lei no 12.403, de 4 de maio de 2011. Altera dispositivos do Decreto-Lei no 3.689, de 3 de outubro de 1941 - Código de Processo Penal, relativos à prisão processual, fiança, liberdade provisória, demais medidas cautelares, e dá outras providências. Subchefia para Assuntos Jurídicos, Brasília, DF, 4 maio 2011. Disponível em: http://www.planalto.gov.br/ccivil_03/_Ato2011-2014/2011/Lei/ L12403.htm. Acesso em: 26 abr. 2019.

CASTELLS, M. O poder da comunicação. São Paulo: Paz e Terra, 2015.

CASTELLS, M. Ruptura: a crise da Democracia Liberal. Rio de Janeiro: Zahar, 2018.

CASTRO, H. C. O. Cultura política comparada: democracia e mudanças econômicas: Brasil, Argentina e Chile. Brasília: Verbena, 2014. CASTRO, H. C. O. A democracia em cheque: um estudo de Cultura Política entre porto-alegrenses. 1996. Dissertação (Mestrado em Ciência Política) - Programa de Pós-Graduação em Ciência Política, Universidade Federal do Rio Grande do Sul, 1996.

CASTRO, H. C. O. Democracy versus people: do changing values challenge Democracy? In: CONGRESSO ANUAL DA WAPOR, 72., 2019, Toronto. Anais [...]. Porto Alegre: UFRGS, 2019.

CASTRO, H. C. de O. de; RANINCHESKI, S.; CAPISTRANO, D. World Values Survey Brazil - Round Seven. Porto Alegre: Ed. da UFRGS, 2018. (Data under embargo for disclosure according to the rules of the World Values Survey Association.). Disponível em: http://www.worldvaluessurvey.org/wvs.jsp. Acesso em: 18 jul. 2019.

CATTERBERG, G.; MORENO, A. The individual bases of political trust: trends in new and established democracies. International Journal of Public Opinion Research, Oxfordshire, v. 18, n. 1, p. 31-48, out. 2005. Disponível em: https://academic.oup.com/ijpor/ article/18/1/31/797103. Acesso em: 26 abr. 2019.

CIFUENTES, P. Investigação na Petrobras começou com um estranho presente de luxo. Brasil El Pais, 2014. Disponível em: https:// brasil.elpais.com/brasil/2014/12/01/politica/1417472349_354451.html. Acesso em: 26 abr. 2019.

INGLEHART, R. et al. World Values Survey: all rounds. Madrid: JD Systems Institute, 2014. Disponível em: http://www.worldvaluessurvey. org/WVSDocumentationWVL.jsp. Acesso em: 26 abr. 2019.

INGLEHART, R. F.; NORRIS, P. Trump, Brexit, and the rise of populism: economic have-nots and cultural Backlash. Harvard Kennedy School: Cambridge, ago. 2016. Disponível em: https://www.hks.harvard.edu/publications/trump-brexit-and-rise-populism-economichave-nots-and-cultural-backlash. Acesso em: 26 abr. 2019.

LEVITSKY, S.; ZIBLATT, D. Como as democracias morrem. Rio de Janeiro: Zahar, 2018.

LIPSET, S. M. O Homem Político. Rio de Janeiro: Zahar, 1967.

MARX, K. A Ideologia Alemã. (Feuerbach). São Paulo: Hucitec, 1986.

MARX, Karl. O 18 de Brumário de Luís Bonaparte. São Paulo: Boitempo, 2011.

MOISÉS, J. A.; MENEGUELLO, R. A Desconfiança política e os seus impactos na qualidade da democracia. São Paulo: Ed. da USP, 2013.

OLIVEIRA, M. Gilmar Mendes suspende nomeação de Lula como ministro da Casa Civil. G1 Globo, Brasília, 18 mar. 2016. Disponível em: http://g1.globo.com/politica/noticia/2016/03/gilmar-mendes-suspende-nomeacao-de-lula-como-ministro-da-casa-civil. html. Acesso em: 26 abr. 2019.

PIKETTY, T. O Capital no Século XXI. Rio de Janeiro: Intrínseca, 2013.

SANTOS, E. R. Poder e Dominação no Brasil: a Escola Superior de Guerra. Porto Alegre: Sulina; Feevale. 2010.

SINGER, A. O Lulismo em Crise: um quebra cabeça do período Dilma (2011-2016). São Paulo: Companhia das Letras, 2018.

VIANNA, L. W. et al. A Judicialização da Política e das Relações Sociais no Brasil. Rio de Janeiro: Revan, 2014.

\section{Notas}

1 Somente o presidente General Figueiredo, no início dos anos 1980, permaneceu, pois era membro de um regime autoritário desde 1964.

2 A estratégia do não impeachment de Temer foi compartilhar o poder com os aliados. Montar uma base que espelhe as preferências ideológicas do plenário (menos heterogênea), compartilhar recursos de acordo com o peso dos partidos no Congresso de maneira muito habilidosa. Temer perdeu completamente o apoio popular com sucessivos escândalos de corrupção, mas se manteve até o final como o apoio do Congresso Nacional. Veja importante artigo explicativo deste fenômeno: "Pagando o preço de governar: custos de gerência de coalizão no presidencialismo brasileiro" (BERTHOLINI; PEREIRA, 2017).

3 Pedalada fiscal foi o termo utilizado para se referir a operações orçamentárias realizadas pelo Tesouro Nacional, não previstas na legislação, que consistem em atrasar o repasse de verba a bancos públicos e privados com a intenção de aliviar a situação fiscal do governo em um determinado mês ou ano. 
4 Este fenômeno estaria substituindo os golpes clássicos do século XX na América Latina que, ao contrário do flagrante descumprimento da lei, que os caracterizava, seria agora a radicalização da lei, porém com os mesmos objetivos, fragilizar a democracia e o espírito das leis.

5 O nome dessa operação deveu-se ao fato de que as investigações descobriram o uso de um posto de gasolina em Brasília para lavagem de dinheiro através de um doleiro chamado Alberto Yossef. Personagem este ligado a Paulo Roberto da Costa, ex-diretor da Petrobrás (CIFUENTES, 2014). Assim, o fio condutor das investigações levou ao coração do Estado neopatrimonial brasileiro.

6 Todavia, agora, em ampla vantagem com relação aos atores políticos, pois trata-se de um ativismo judicial, a entrada no jogo eleitoral abertamente.

7 A articulação da justiça, do Ministério Público, da Política Federal, conforme aquilo que Singer (2018) chamou de o partido da justiça.

8 Não se quer com esta análise desse fenômeno eximir algum político ou mesmo a classe política de suas defecções. No Brasil, a corrupção é proporcional ao nível de inserção do político no Estado brasileiro. Decerto que um presidente da República poderá ser acusado de malversação do dinheiro público de uma grande empresa petrolífera, tráfego de influência, ao passo que um deputado federal poderá ser acusado de empregar funcionária fantasma em seu gabinete através da conhecida rachadinha. Muito embora Lula e Bolsonaro estejam há décadas na política, o deputado Bolsonaro integrava o baixo clero no Congresso Nacional e suas posições extremadas e exóticas sempre o insularam da participação direta em diferentes governos e ministérios, também o alijando da participação maior na corrupção nacional, tal como o PT e seus partidos aliados: era periférico na política e na corrupção.

\section{Everton Rodrigo Santos}

chabert89@gmail.com

Doutor em Ciência Política pela Universidade Federal do Rio Grande do Sul (UFRS)

Professor do Programa de Pós-Graduação em Diversidade Cultural e Inclusão Social da Universidade

Feevale

\section{Feevale}

ERS-239,N. 2755

Novo Hamburgo - R.S - Brasil

CEP: 9352-075

\section{Henrique Carlos de O. de Castro}

henrique@ufrgs.br

Doutor em Ciência Política pela Universidade Federal do Rio Grande do Sul (UFRS)

Professor do Departamento de Economia e Relações Internacionais e do Programa de Pós-Graduação em Ciência Política da Universidade Federal do Rio Grande do Sul (UFRS)

\section{UFRGS/DERI}

Av. João Pessoa, 52.

Centro - Porto Alegre/RS

CEP: 90040-000.

\section{Fábio Hoffmann}

molahms@gmail.com

Mestre em Ciência Política pela Universidade Federal de Pelotas (UFPel)

\section{UFPel}

Av. Borges de Medeiros, N. 915, Centro histórico.

Porto Alegre - R.S - Brasil

CEP: 90020-025 


\section{Agradecimentos}

Não se aplica.

Agência financiadora

Não se aplica.

Contribuições dos autores

Revisão teórica e análise final dos dados pelos três autores.
Aprovação por Comitê de Ética e consentimento para participação

CNPQ.

Consentimento para publicação

Consentimento dos autores.

Conflito de interesses

Não há conflito de interesses. 